\title{
Calculation of danger level of pedestrian crossings
}

\author{
S.M. Porkhacheva \\ Federal State - funded Educational Establishment of Higher \\ Education «Siberian State University of Highways» \\ Omsk city, Russia \\ e-mail: svetlanam82@mail.ru
}

\begin{abstract}
The present article is devoted to description of some major factors influencing the danger of a pedestrian crossings zone. The review of the factors affecting the number of «vehicles - pedestrians» conflicts in the pedestrian crossing zone was performed. An example of the developed program for determining the danger level of pedestrian crossings on the main streets was given.
\end{abstract}

Keywords - a pedestrian crossing; danger level; width of a pedestrian crossing; road signs; a program for calculation of the danger level of pedestrian crossings.

\section{INTRODUCTION}

Pedestrian crossings are the place designed for pedestrians to cross a road. It is obligatory to fulfill the requirements of some regulatory documents to provide the traffic safety $[1,2$, 3]. These requirements are:

- ensuring visibility conditions;

- ensuring pedestrian crossings with proper traffic management facilities;

- ensuring a sufficient number of pedestrian crossings along the highway;

- ensuring a sufficient width of the pedestrian crossing depending on the intensity of the pedestrian flow.

Some academic papers were devoted to the study of influence of pedestrian flow parameters and the arrangement of pedestrian crossings on the number of conflicts among them $[4,5,6,7,8,9,10]$. The author obtained the following results during the research $[11,12,13]$ :

- the dependencies of the influence of certain factors on the number of conflicts in the zone of pedestrian crossings were established;

- the index of danger of a pedestrian crossing was developed;

- recommendations for pedestrian crossings placement depending on the category of streets and roads were developed.

The above listed results were used for the further reference which was the development of the program for determining the danger level of pedestrian crossings.

\author{
M.G. Simul \\ Federal State - funded Educational Establishment of Higher \\ Education «Siberian State University of Highways» \\ Omsk city, Russia \\ e-mail:simul79@yandex.ru
}

\section{RESULTS OF THE RESEARCH}

A conflict is understood as the situation when drivers did not give pedestrians the first right of way at the pedestrian crossing. Such a right is granted to pedestrians on the basis of the Rules of the Road [14].

The resulting characteristic $\mathrm{Y}$ is the average number of «vehicles - pedestrians» conflicts per hour expressed as the drivers' non-compliance with the requirements of the technical means of traffic organization while passing pedestrian crossings.

The factor characteristics for the signal-controlled pedestrian crossings are the following:

$X_{1}$ - the length of safety fences;

$X_{2}$ - the width of a pedestrian crossing;

$X_{3}$ - the distance to the nearest public transport stop;

$X_{4}$ - the distance between the pedestrian crossings located one after another along the highway.

The factor characteristics for zebra crosswalks are:

$X_{5}$ - the width of a pedestrian crossing;

$X_{6}$ - the width of a road;

$X_{7}$ - pedestrian flow intensity;

$X_{8}$ - the distance to an underground walkway.

The multiplicative model for the factors under consideration and the resulting characteristic is the following:

- for signal-controlled pedestrian crossings:

$$
\begin{aligned}
& Y\left(X_{i j}\right)=X_{1}^{\alpha 1} X_{2}^{\alpha 2} X_{3}^{\alpha 3} X_{4}^{\alpha 4} \text {; } \\
& \text { - for zebra crosswalks: } \\
& Y\left(X_{i j}\right)=X_{5}^{\alpha 5} X_{6}{ }^{\alpha 6} X_{7} \alpha{ }^{\alpha 7}{ }_{8}^{\alpha 8} \text {, }
\end{aligned}
$$

where $Y$ is the value of the resulting characteristic for the period of time $j$ from the factor $X_{\mathrm{i}}, i=1,2, \ldots, 8 ; \alpha_{1}-\alpha_{8}$ are weight coefficients of the factor $i$ considered by the model. 
The list of the factors for the models represented by the equations (1) and (2) is given in Table 1 below:

TABLE I. THE LIMITS OF FACTOR CHARACTERISTICS VARIATIONS IN EXPERIMENTAL RESEARCH

\begin{tabular}{|l|c|l|c|}
\hline \multicolumn{1}{|c|}{ Signal-controlled pedestrian crossings } & \multicolumn{2}{c|}{ Zebra crosswalks } \\
\hline $\begin{array}{l}\text { Length of safety } \\
\text { fences } X_{1}\end{array}$ & $8-3600 \mathrm{~m}$ & $\begin{array}{l}\text { Factor } \\
\text { pedestrian crossing } \\
X_{5}\end{array}$ & $2,5-5 \mathrm{~m}$ \\
\hline $\begin{array}{l}\text { Width of a pedestrian } \\
\text { crossing } X_{2}\end{array}$ & $3-9 \mathrm{~m}$ & Width of a road $X_{6}$ & $7-22 \mathrm{~m}$ \\
\hline $\begin{array}{l}\text { Distance to the nearest } \\
\text { public transport stop } \\
X_{3}\end{array}$ & $8-600 \mathrm{~m}$ & $\begin{array}{l}\text { Pedestrian flow } \\
\text { intensity } X_{7}\end{array}$ & $\begin{array}{c}20-1500 \\
\text { people/hour } \\
\text { (both } \\
\text { directions) }\end{array}$ \\
\hline $\begin{array}{l}\text { Distance between the } \\
\text { pedestrian crossings } \\
\text { located one after } \\
\text { another along the } \\
\text { highway } X_{4}\end{array}$ & $100-1400$ & $\begin{array}{l}\text { Distance to an } \\
\text { underground } \\
\text { walkway } X_{8}\end{array}$ & $\begin{array}{c}100-1400 \\
\mathrm{~m}\end{array}$ \\
\hline \multicolumn{2}{|l}{} & \multicolumn{2}{|c}{} \\
\hline
\end{tabular}

To investigate the relationship among the factors included into the multiplicative model, the correlation matrices were created. They allowed to establish the existence of correlation relationships between the resulting and factor characteristics. Calculation of paired correlation coefficients was carried out using the Microsoft Excel package.

The correlation matrix for signal-controlled pedestrian crossings and the period of time from $3 \mathrm{pm}$ to $4 \mathrm{pm}$ is provided in Table 2 .

TABLE II. MATRIX OF PAIRED CORRELATION COEFFICIENTS FOR SIGNAL-CONTROLLED PEDESTRIAN CROSSINGS

\begin{tabular}{|c|c|c|c|c|c|}
\hline & $\boldsymbol{X}_{\mathbf{1}}$ & $\boldsymbol{X}_{\mathbf{2}}$ & $\boldsymbol{X}_{\mathbf{3}}$ & $\boldsymbol{X}_{\mathbf{4}}$ & $\boldsymbol{Y}\left(\mathbf{X}_{\mathbf{i 1}}\right)$ \\
\hline $\boldsymbol{X}_{\mathbf{1}}$ & 1 & & & & \\
\hline $\boldsymbol{X}_{\mathbf{2}}$ & 0,99 & 1 & & & \\
\hline $\boldsymbol{X}_{\mathbf{3}}$ & 0,99 & 0,99 & 1 & & \\
\hline $\boldsymbol{X}_{\mathbf{4}}$ & 0,99 & 0,99 & 0,98 & 1 & \\
\hline $\boldsymbol{Y}\left(\boldsymbol{X}_{i 1}\right)$ & $-0,79$ & $-0,79$ & $-0,75$ & $-0,75$ & 1 \\
\hline
\end{tabular}

TABLE III. VALUES OF WEIGHT COEFFICIENTS FOR SIGNALCONTROLLED PEDESTRIAN CROSSINGS FROM FACTORS

\begin{tabular}{|c|c|c|c|c|}
\hline \multirow{2}{*}{ Value } & $\boldsymbol{\alpha}_{\mathbf{1}}$ & $\boldsymbol{\alpha}_{\mathbf{2}}$ & $\boldsymbol{\alpha}_{\mathbf{3}}$ & $\boldsymbol{\alpha}_{\mathbf{4}}$ \\
\cline { 2 - 5 } & 0,26 & 0,26 & 0,24 & 0,24 \\
\hline
\end{tabular}

The final number of conflicts on the signal-controlled pedestrian crossings depending on the value of the factors under consideration can be calculated as follows:

$$
\hat{Y}\left(X_{i 1}\right)=\frac{1}{X_{1}^{0,26} X_{2}^{0,26} X_{3}^{0,24} X_{4}^{0,24}} .
$$

An example of the dependence of the number of conflicts on various factors included in Table 1 is shown in Figure 1. These dependencies were obtained by processing experimental data of the survey of pedestrian crossings on the main roads of Omsk city.
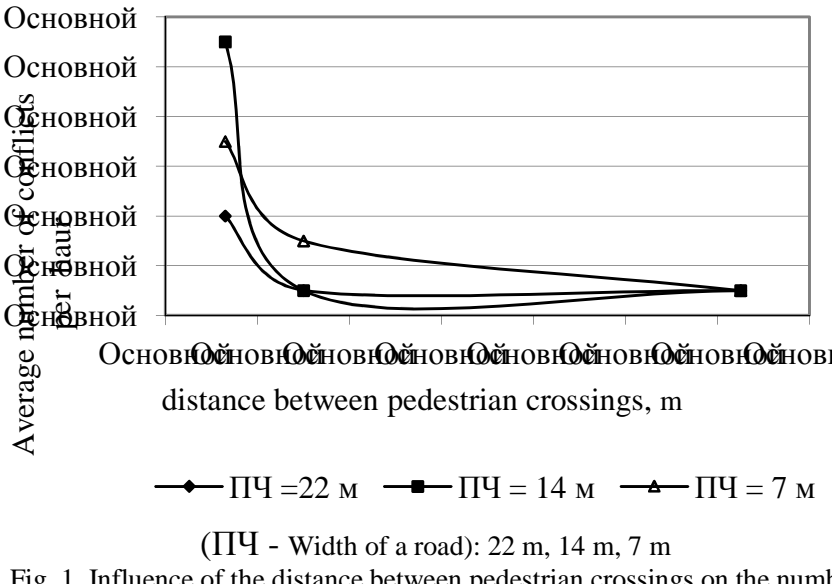

Fig. 1. Influence of the distance between pedestrian crossings on the number of conflicts

As a criterion for assessment of the effectiveness of measures on pedestrian crossings placement may be the danger level coefficient ( $\mathrm{C}$ dan) of a pedestrian crossing equal to the ratio of the number of conflicts per day to the average annual number of road traffic accidents $\left(\mathrm{N}_{\mathrm{RTA}}\right)$ at a pedestrian crossing.

$$
\mathrm{C} \text { dan }=\frac{\mathrm{N}_{\mathrm{c}}}{\mathrm{N}_{\mathrm{RTA}}},
$$

where $\mathrm{N}_{\mathrm{c}}$ is the average number of conflicts per day at the pedestrian crossing, NRTA is the average annual number of road traffic accidents at a pedestrian crossing.

From the daily number of conflicts we can go to the average annual one by the following ratio:

$$
N=\mathrm{Nc} \bullet \beta \bullet 365,
$$

where $N c$ is the number of conflicts within 1 hour in the rush hour period; $\beta$ is the coefficient of daily inequality of vehicles and pedestrians intensity.

It is necessary to assess the danger of pedestrian crossings by three levels:

A - from 0 to 1 - «low level of danger» - pedestrian crossings do not need reconstruction or relocation;

$\mathrm{B}$ - from 1 to 3 - «medium level of danger» - pedestrian crossings need additional equipment with the necessary traffic management facilities, which will improve the traffic safety;

$\mathrm{C}$ - over 3 - «high level of danger» - it is recommended to dismantle pedestrian crossings or move them to a safer section of the highway.

\section{RESULTS OF THE RESEARCH AND THEIR FURTHER REFERENCES}

Recommendations for pedestrian crossings placement are based on the application of two targeted indicators: 
_ the number of «vehicles - pedestrians» conflicts;

- $\quad$ speed of vehicles on the main streets.

The condition for the first indicator is to reduce such conflicts, and for the second one - to increase the speed of vehicles on the main streets. Taking into account these targets and based on the results of the held experimental research, the recommendations can be formulated as follows:

- the distance between the signal-controlled pedestrian crossings following one after another must be set in the range from 600 to $900 \mathrm{~m}$ - for the main roads with regulated traffic and for transport and pedestrian roads of district status;

- the distance between the ground level pedestrian crossing and the underground crosswalk adjacent to it must be set in the range of 1000-1500 $\mathrm{m}$ - for the main roads with regulated traffic and for transport and pedestrian roads of district status (pedestrian flow intensity is 600-800 people/hour, the distance to a passenger transport stop - up to $130 \mathrm{~m}$ );

- the distance between the nearest passenger transport stop and a ground level pedestrian crossing must be set in the range from 200 to $400 \mathrm{~m}$ - for roads of district status (with a roadway width equal to $7-14 \mathrm{~m}$ );

- the value of the traffic flow speed is most influenced by the width of a pedestrian crossing; with an increase in the width of a pedestrian crossing by $1 \mathrm{~m}$ the speed of the transport flow decreases by an average of $2.5 \mathrm{~km} / \mathrm{h}$.

The programme «Pedestrian crossing» was created in the Visual Basic 6.0 programming environment. The structure of the program is a set of forms connected with one another by jump buttons. The program has the shell containing the system folder «SYSTEM» and the executable file «Pedestrian crossing.exe» designed to run the program, which is to display the main program window on the screen, see Fig. 2.

\begin{tabular}{|cc|}
\hline PEDESTRIAN & \\
CROSSING & \\
& \\
& NEXT \\
\hline
\end{tabular}

Fig. 2. Main window of the interactive program "Zagruzka" ("Loading")

In the lower right corner, there is the "Next" button to go to the selection of calculation programs. In the dialog box of the program, there are some options for equipping pedestrian crossings in the road network. According to these options the method for determining the pedestrian crossing danger level is chosen (Fig. 3). Then it is necessary to fill in the field of initial data according to the chosen method of calculation of the pedestrian crossing danger level. The list of source data varies depending on the type of pedestrian crossing arrangement (Fig. 4).
Calculation for a signal-controlled pedestrian crossing

\section{Calculation for a zebra crosswalk}

Exit

Fig. 3. Window of selection of the calculation method of the program "Pedestrian crossing"

Initial data for a signal-controlled pedestrian crossing

Please enter the initial data

Location of the pedestrian crossing Prospekt Mira St., 58

Length of safety fences, $\mathrm{m}$

Width of the pedestrian crossing, $\mathrm{m}$

Distance to the nearest public transport stop, $\mathrm{m}$

Distance between the pedestrian crossings located one after another along the highway, $\mathrm{m}$

Number of road traffic accidents (annual)

GO TO THE TYPE OF

A PEDESTRIAN CROSSING CALCULATION

Initial data for a zebra crosswalk

Please enter the initial data

Width of a pedestrian crossing, $\mathrm{m}$

Width of a road, $\mathrm{m}$

Pedestrian flow intensity, people/hour

Distance to an underground walkway, $\mathrm{m}$

Number of road traffic accidents (annual)

GO TO THE TYPE OF

A PEDESTRIAN CROSSING

CALCULATION

Fig. 4. Windows for entering initial data in the program "Pedestrian crossing" for a signal-controlled pedestrian crossing and a zebra crosswalk relatively.

After filling in the fields of the initial data, you should click the «Calculation» button (Fig. 5). In the dialog box of the program, you can see the results of the calculation of the pedestrian crossing danger level. In accordance with the danger level, the program forms a list of recommended measures to reduce the impact of the identified danger factors (see Fig. 6). 
Initial data for a signal-controlled pedestrian crossing

Please enter the initial data

Length of safety fences, m $\underline{100}$

Width of the pedestrian crossing, $\mathrm{m} \underline{14}$

\begin{tabular}{l} 
ERROR \\
Invalid value! \\
Valid range is between 3 and $9 \mathrm{~m}$ \\
OK \\
\hline
\end{tabular}

Distance to the nearest public transport stop, $\mathrm{m} \underline{100}$

Distance between the pedestrian crossings located one after another along the highway, $\mathrm{m} 100$

Number of road traffic accidents (annual) $\underline{8}$

\section{GO TO THE TYPE OF}

\section{A PEDESTRIAN CROSSING}

\section{CALCULATION}

Fig. 5. An example of the wrong fulfillment of the initial data field.

Results of the calculation and conclusions

Number of conflict situations $=78$

High level of danger of the pedestrian crossing. It is recommended to dismantle the pedestrian crossing or to move it to a safer section of the highway.

Back to initial data

Exit

Fig. 6. Window of showing results of the calculation in the program "Pedestrian crossing"

\section{CONCLUSIONS}

The held studies of the influence of some factors on the danger level in the zone of pedestrian crossings allowed making the following conclusions and recommendations:

- to determine the range of the influence of certain factors on the number of conflicts occurring at pedestrian crossings;

- to develop the models for defining the number of conflicts at pedestrian crossings;

- $\quad$ to develop a criterion for assessing the danger level of pedestrian crossings;

- to formulate recommendations on the location of pedestrian crossings on highways;

- to develop the program for calculation of the pedestrian crossings danger level.

The application of these recommendations helps to assess the danger of pedestrian crossings, to plan some actions for traffic safety improvement (to reduce the number of conflicts), and the developed program allows one to perform these calculations with less labor costs.

\section{References}

[1] GOST R 52289-2004, Traffic management facilities. Rules of application of road signs, markings, traffic lights, road safety fences and guiding devices, Introduced on Jan 01, 2006, Moscow: Standartinform, 2005.

[2] GOST R 52766-2007, Public roads. Elements of arrangement. General requirements, Introduced on July 01, 2008, Moscow: Standartinform, 2008.

[3] SanPiN (Sanitary Rules and Norms) 42.13330.2011, Urban planning. Planning and development of urban and rural settlements: Updated version of SNiP 2.07.01 -89, Document from the Information Retrieval System «Codex».

[4] A.Yu. Mikhailov, I. M. Golovnykh, Modern trends in design and reconstruction of street-road networks of cities,Novosibirsk: Science, 2004, pp. 134-139.

[5] V. Gitelman, R. Carmel, F. Pesahov, S. Hakkert, "An examination of the influence of crosswalk marking removal on pedestrian safety as reflected in road user behaviours," Transportation Research Part F: Traffic Psychology and Behaviour, Vol. 46, Part B, pp. 342-355, April 2017.

[6] G. Xiaoping, Michael C. Dunne, John A. Black, "Modeling of Pedestrian Delays with Pulsed Vehicular Traffic Flow," Transportation Science, Vol. 38, No. 1 (February), pp. 86-96, 2004.

[7] L. Lu, G. Ren, W. Wang, Ching-Yao Chan, "Application of SFCA pedestrian simulation model to the signalized crosswalk width design," Transportation Research Part A: Policy and Practice, Vol. 80, pp. 76-89, October 2015.

[8] T. Fu, L. Miranda-Moreno, N. Saunier, "A novel framework to evaluate pedestrian safety at non-signalized locations," Accident Analysis \& Prevention, 2018, Vol. 111, pp. 23-33, February 2018.

[9] A.H. Mohammadipour, Seyed Hafez Alavi, "The analysis of the geometric cross-section of the pedestrian crosswalks: A case study in Qazvin," Accident Analysis \& Prevention, Vol. 41, Issue 2 (March), pp. 314-326, 2009.

[10] Y. Li, Geoff Fernie, "Pedestrian behavior and safety on a two-stage crossing with a center of a refugee and the effect of a winter on a pedestrian compliance rate," Accident Analysis \& Prevention, Vol. 42, Issue 4 (July), pp. 1156-1163, 2010.

[11] M.G. Simul, "Placement of pedestrian crossings at city highways", Materials of the first international scientific and practical conference. (Surgut, April 18-20, 2012), Omsk: SibADI, pp. 99-103, 2012.

[12] M.G. Simul, "Assessment of the pedestrian crossings danger level on the main streets", Materials of XII international correspondence. Scientific and practical conference. Part 1 (September 17, 2012), Novosibirsk: Ed. "Siberian Association of Consultants", pp. 74 -78, 2012.

[13] E.E. Vytvitsky, S.M. Porkhacheva, M.G. Simul, "Innovative technology for determining the traffic capacity of street network elements", Book of reports of 12th International Scientific and Practical Conference «Traffic Organization in Large Cities», St. Petersburg, September 28-30, pp. 579 $584,2016$.

[14] Rules of the Road: approved by the Council of Ministers - Government Decree 23.10.1993: as of 15.06.2015, Moscow. Mir Avtoknig, 2015, 64 p. 